\title{
The Correct Ladder to Achieve Academic Laurels
}

\author{
Zahid Hussain Khan (iD ${ }^{1,2,}{ }^{*}$, Hooshang Saberi ${ }^{2}$ and Nazi Derakhshanrad ${ }^{2}$ \\ ${ }^{1}$ Department of Anesthesiology, Imam Khomeini Hospital, Tehran University of Medical Sciences, Tehran, Iran \\ ${ }^{2}$ Department of Neurosurgery, Imam Khomeini Hospital, Tehran University of Medical Sciences, Tehran, Iran \\ "Corresponding author: Department of Anesthesiology, Imam Khomeini Hospital, Tehran University of Medical Sciences, Tehran, Iran. Email: khanzh51@yahoo.com
}

Received 2021 March 01; Accepted 2021 March 02.

Keywords: Academic Laurels, Promotion, Ethical Standards, Illicit Means

Academic promotion has always been amongst the favorite dreams of faculty members and is encouraged by medical universities. Some of these achievements may find their true place if a chair is defined for a highly capable faculty so that the spirit of competition remains alive and rivalries are altogether banished.

The dignity, grandeur, and reputation of an academician is related to the magnitude, scope, and spectrum of his/her thinking capabilities, intuitive powers, and their wise application in academic pursuits. The vaster the horizon of thinking, the greater would be the dignity of an academician. Individuals who are humble would achieve higher distinctions because of their ability to exploit their capabilities of thinking, intuition, understanding, and perception in contrast to their self-centered colleagues. Intellectuals who have managed to come out of this web of selfishness have a wider horizon of thinking and thus are able to sparkle their intellectual powers in the greater interest of the students in general and the society in particular. Scientists who have a knack and potential to excel in their specialty help in resolving the needs of people, and as such, have a distinct and vast horizon of thinking. They ponder over debatable theories, concepts, propositions, and hypotheses and are determined to find acceptable and plausible solutions to the thorny and difficult questions. Thus, dignity and grandeur totally depend on creative, innovative, and ethical standards, which are invariably found in dedicated researchers, artists, writers, scientists, and thinkers. Worldly gains, positions, aspirations, and a narrowed vision and contracted thinking are not the parameters of dignity, splendor, and pride. The decadent ideologies and doctrines revolving around the matrix of money, wealth, and subjugation have been established as the root causes of the multifarious ills found in some societies.

Despite the endeavors of man to achieve the most acceptable standards of life, most of us fall short of them because of the innumerable and countless factors in life which impede our progress. It is because of these inevitable multifaceted circumstances that human beings do not develop the slightest resemblance to one another and fall into diversified personalities. Depending on one's inclination to satiate his/her SELF (S) or love for OTHER(O), people can be divided into four groups as follows: group I $=+S+O$, group II $=+S-O$, group III $=-S+O$, and group IV $=-S$ $-\mathrm{O}$.

The first group has a definite entity and ideology along with an authentic and tentative school of thought. Such a person looks at life from a calculated perspective and toils to make it worth living for others. Such a person shines to light and paves the way for others and brittles but does not endeavor to excel others. On the contrary, for such a person, the concept of life is to live for others and to apprise them of the good values of life as depicted in the holy and heavenly books. The prophets and saints fall into this category. Their ties with others are for the sole and explicit purpose of pursuing and wage war against social ills, decadent values, and tyranny. The second group contrives to establish a network of unhealthy communications to grind its own axe. This type of personality has his/her own self-contrived and self-made ideology totally devoid of a definite and recognized school of thought. The links of such individuals with others are to reap benefits and dividends and not at all to give others their due share. They want to have a magnificent, posh, and lavish living at the expense of others; such characters and entities are rampant in every society, and particularly in the so-called advanced and civilized western societies. The third group 
comprises persons who conduct their responsibilities and obligations well as laid down by the society. However, these persons do not go any further other than performing their task assigned to them and thus lag behind others as far as progress in academic pursuits, and life is concerned. People keep these persons in their good books; although their overall impact on others and on society is perceivable, it is perishable. It is because of these reasons that they are hardly ever remembered other than by a small and limited number of people. The fourth group includes the people who fail to play a constructive role in society due to the stroke of fate or other factors. As they are indifferent and docile, they neither take an interest in their own self nor can offer any service to others.

For scientists, self-satisfaction is one of the important factors to survive. Progression in one's career and life brings satisfaction, and it is an obligatory process in life. A stop or halt in this process leads to dissatisfaction and ultimately results in depression. The more progress you make, the more your mood gets elevated. However, to make progress, the seniors should try to help their juniors to reach the higher ranks in the society, and the juniors should also pay back the generosity of their seniors in similar or exalted means to please them. If we abide by this simple principle, we would progress in life. On the contrary, if we fail to abide by it, we would suffer and receive severe and irrevocable setbacks in our career.

However, there are many personalities in the departments who are always considerate in their dealings with their fellow colleagues, especially the senior ones. In contrast, you realize how inconsiderate, irrational, indelicate, and unfeeling their conduct has been at times. It is here where all the ethical standards and professional ethics are totally trampled to achieve one's own aspirations, but unfortunately, with nefarious designs. Some of these people cut life to pieces with their epigrams and satirical remarks. Furthermore, they play vile force against all norms of ethical standards to reach their goals, and unfortunately, this is the sad sage of human vociferous appetite.

History is full of instances where unwanted ambition has wrought havoc. For instance, Lady Macbeth forgoes normal feminine traits like motherly compassion to more masculine ones like ambition, which leads to the collapse of her family.

To catch the nearest way. Thou wouldst be great.

Are not without ambition, but without the illness should attend it (1).

If we cast an eye at the philosophers in the bygone times, it would dawn on us that, like most ancient philoso- phers, Plato maintains a virtue-based eudemonistic conception of ethics. In simple words, happiness or well-being (eudaimonia) is the highest and supreme mode of moral thought and conduct, and the virtues ('excellence') are the requisite skills and the highly needed dispositions to attain it (2).

In conclusion, the whole drama of life is a complicated charade. If we, as academicians, walk gingerly and with utmost care and precision, and in total compliance, within the framework of professional, ethical standards, we would achieve the zenith of glory and excellence. However, if we adopt nefarious, illicit, and unethical means in achieving the loftiest goals in life in general, and academic pursuits in particular, we are bound to meet a head-on collision, and as a consequence, disappear and get trampled by that constant and invisible watch that is always kept on our misdemeanor and wrong deeds. As stated by thinkers and philosophers in the past, the pioneers should be remembered and extolled while presenting one's achievements in contemporary literature. Saadi, the famous mystic Persian poet depicts the whole philosophy as follows:

If you wish to have your name eternal,

Hide not the good-name of great men.

One took a good name out of the world,

One's evil ways remained after him (3).

\section{Footnotes}

Authors' Contribution: Study concept and design: ZHK and HS. Drafting of the manuscript: ZHK, HS, and ND. Critical revision of the manuscript for important intellectual content: ZHK and HS.

Conflict of Interests: None of the authors acknowledge and declare any potential conflicting interest.

Funding/Support: None of the authors acknowledge and declare any sources of funding.

\section{References}

1. Shakespeare W, Mowat BA, Werstine P. The tragedy of Macbeth. Folger Shakespeare Library. New York: Simon \& Schuster Paperbacks; 2013. p. 31-3.

2. Annas J. An introduction to Plato's republic. 1st ed. Oxford University Press; 1981. p. 98-101.

3. Saadi Shirazi SM. On justice, management, and good judgment. The Bustan of Saadi. Translated by Hart Edwards A. Bibliotech Press; 2018. 